\title{
Context Matters for Preschool Discipline: Effects of Distance Learning and
}

\section{Pandemic Fears}

Brita A. Bookser ${ }^{1}$, Michael Ruiz ${ }^{2}$, Ayomide Olu-Odumosu ${ }^{2}$, Moonhawk Kim³ ${ }^{3}$ Shoshana N.

\author{
Jarvis $^{4}$, and Jason A. Okonofua ${ }^{2}$ \\ ${ }^{1}$ School of Social Welfare, University of California, Berkeley \\ ${ }^{2}$ Department of Psychology, University of California, Berkeley \\ ${ }^{3}$ Graduate School of Education, University of California, Berkeley \\ ${ }^{4}$ Haas School of Business, University of California, Berkeley
}

\section{Accepted for Publication at School Psychology}

This version is not the copy of record and may not exactly replicate the final version of the article. The final article is available via its DOI: $10.1037 /$ spq0000452

Author Note: We would like to acknowledge our district partners and we thank the peer reviewers for their generous and constructive feedback. This research was funded in full through university faculty funding to Jason A. Okonofua. Shoshana N. Jarvis is supported by a National Science Foundation Graduate Research Fellowship DGE 1752814. We have no conflicts of interest to disclose. The authors do not have any closely related manuscripts that have been submitted or published simultaneously or previously for consideration by another journal. All procedures performed in this study involving human participants were approved by the Institutional Review Board for the University of California, Berkeley. The contents of the manuscript (including the treatment of participants) are consistent with the APA Ethical Principles of Psychologists and Code of Conduct pertaining to Research Publication.

Correspondence concerning this article should be addressed to Brita A. Bookser, School of Social Welfare, 120 Haviland Hall, Berkeley, CA 94704. Email: britabookser@berkeley.edu 


\begin{abstract}
The COVID-19 pandemic transformed the context and delivery of early childhood education, yet little is known about its impact on exclusionary discipline (e.g., suspension, expulsion), which nationally representative evidence has shown disproportionately impacts Black boys. Using one experiment, we test how preschool providers respond to three hypothetical vignettes about a Black boy's behaviors. Participants $(N=60)$ were randomly assigned to read vignettes set in either distance learning or in-person classroom contexts. Then, participants completed measures about discipline and COVID-19. Results indicated there was an interaction between context and the sequence of vignettes on providers' troubled feelings and endorsements of discipline. Providers showed heightened troubled feelings and endorsements of discipline severity in the distance learning context, as compared to an in-person context, as vignettes progressed. Additionally, the more providers feared COVID-19, the more they felt troubled over the course of the vignettes across conditions. Practitioners can use this research to inform consultative interventions that mitigate discipline by directly addressing providers' pandemic fears and classroom contexts.
\end{abstract}

Keywords: exclusionary discipline, early childhood education, teachers, COVID-19, distance learning 


\section{Impact and Implications Statement}

This experiment found that over the course of three hypothetical vignettes about a Black boy's behaviors, preschool providers tended to feel more troubled and endorse more severe discipline in a distance learning context, as compared to an in-person context, and when they were more fearful of COVID-19. Interventions should directly address providers' experiences and classroom contexts to mitigate discipline and enhance early educational equity. 


\section{Context Matters for Preschool Discipline: Effects of Distance Learning and Pandemic Fears}

Early childhood education can have positive, lasting impacts on individuals and society (Barnett, 1998; Yoshikawa et al., 2013). Yet it is not equitably accessible or effective (Barnett, 2011; Pianta et al., 2009). Seminal research has shown that a sizable proportion of children miss early childhood education opportunities due to exclusionary discipline (e.g., suspension, expulsion). Exclusionary discipline in K-12 is associated with a host of adverse outcomes that disproportionately affect Black students, including missed opportunities to learn and lower academic performance (Lewis et al., 2010; Losen \& Whitaker, 2018), as well as greater risk for police stops and arrests (Barnes \& Motz, 2018; Jackson et al., 2021). Racial disparities in school discipline among preschool populations would suggest that Black children are tracked toward adverse outcomes early in life.

National and state-level estimates indicate preschoolers are expelled at a rate more than three times as great as K-12 students (Gilliam, 2005; Gilliam \& Shahar, 2006). Black children, especially boys, are disproportionately expelled in preschool compared to their White and Asian peers (Gilliam, 2005), replicating discipline disparities well-documented in K-12 research (see Gregory et al., 2010 for review). Further, estimates from the 2017-2018 Civil Rights Data Collection survey indicate Black boys were suspended at a rate 2.7 times as great as their White peers in preschool, and though Black males represented approximately $18 \%$ of male preschool enrollment, they comprised approximately $41 \%$ of male children suspended (U.S. Department of Education, 2021). ${ }^{1}$ A robust literature has sought to understand mechanisms of discipline disparities in the K-12 context, yet evidence of mechanisms in the preschool context is nascent. 
The most recent pandemic, COVID-19, brings educational equity issues into sharp relief. In the spring of 2020, school districts across the United States rapidly shifted the context of public education from in-person to virtual platforms, generally referred to as "distance learning." Evidence has shown that the pandemic disproportionately impacted racially/ethnically minoritized, low-income, immigrant, rural, and other marginalized communities (Mueller et al., 2020; Quandt et al., 2020), exacerbating preexisting social inequities (Prime et al., 2020; Silverman et al., 2020). School closures, shifts in classroom contexts, and implementation of social distance measures carried consequences across the early childhood education ecology. Yet, it is not clear whether the pandemic, generally, and its transformation of the education context, specifically, affect disciplinary decisions. Past research suggests perceptions of and responses to behavior are pivotal factors to discipline decisions (Okonofua et al., 2016) and classic social psychological theory posits context shapes individuals' perceptions and decisionmaking (e.g., Darley \& Gross, 1983). We strategically integrate these previous theories and findings with social psychological methods and a critical theoretical perspective.

This paper responds to a need for justice-driven, inclusive research that expands knowledge about exclusionary discipline on an ecological scale amid the extraordinary context of COVID-19. Disability Critical Race Theory (DisCrit; Annamma et al., 2013) frames our discussion of the implications of this research. DisCrit is instructive because it troubles notions of normalcy as socially constructed, inflected by and interdependent upon racism and ableism (Annamma et al., 2013). Narrow tolerance or accommodation of varied child behaviors normalize practices that may not be developmentally appropriate for young children (Wood et al., 2017) and may contribute to an anti-Black climate in early childhood classrooms (Boutte \& Bryan, 2019). This paper aims to generate practice-relevant insights for clinical practitioners and 
educational providers to mitigate discipline and support equitable, accessible, and inclusive early childhood education.

\section{Subjective Interpretations and Disproportionate Discipline of Black Boys}

Mounting evidence indicates that teachers' and principals' subjective interpretations of student behaviors partially explain racial and gender disparities in school discipline (e.g., Girvan et al., 2017; Jarvis \& Okonofua, 2020). For instance, multilevel models of state data indicated that school-level variables (e.g., principals' perspectives on school discipline) contributed to racial disparities in exclusionary discipline far more than student-level variables, including type of infraction or individual demographics (Skiba et al., 2014). Similarly, a comprehensive literature review revealed that school and classroom factors (e.g., teachers' perspectives) accounted for discipline disparities among students from minority and low-socioeconomic groups, while student behavior and socioeconomic status did not fully explain variance in school discipline (Welsh \& Little, 2018).

Emerging research has focused on the links between early childhood educators' perspectives on child behavior and exclusionary discipline. For instance, qualitative research examining children's paths toward expulsion showed that teachers' frustration and exhaustion with persistent challenging behaviors led them to complain to school leaders, miss work, and threaten to quit (Martin et al., 2018). Further, teachers' perceptions of children's behaviors escalated in severity over time, transforming from "challenging" to "unsafe" and "dangerous" (Martin et al., 2018, p. 93). Moreover, a validation study of a measure assessing preschool expulsion risk found that teachers' decisions about expulsion were shaped by children's behaviors that were viewed as disruptive to the classroom (e.g., interfered with teaching or 
classroom management), and the extent that these behaviors influenced teachers' fears of accountability, hopelessness, and stress (Gilliam \& Reyes, 2018).

\section{Racial Stereotypes}

One explanation of teachers' subjective interpretations and differential treatment of Black boys posits that their perspectives are influenced by racial stereotypes (Okonofua \& Eberhardt, 2015; Wood et al., 2017). Transdisciplinary research using methods that prime race demonstrates that racial stereotypes predict punitiveness in school disciplinary action (Hannon et al., 2013;

Okonofua \& Eberhardt, 2015), prison sentencing (Eberhardt et al., 2006), police violence against youth (Goff et al., 2014). Racial stereotypes construct Black boys as troublesome, threatening, and in need of more control and harsher punishment compared to their peers (Monroe, 2005). In one study, when preschool teachers scanned a classroom video scene for misbehavior, they spent significantly more time watching Black children, especially Black boys, compared to White children (Gilliam et al., 2016).

Racial stereotypes appear to drive educators' perspectives on discipline over the course of multiple misbehaviors. In the K-12 context, Okonofua and Eberhardt (2015) conducted two experimental studies that focused on teachers' perspectives on student misbehavior. The authors hypothesized that negative racial stereotypes associated with Black students would increase the likelihood that teachers viewed multiple infractions over time as a problematic pattern, potentially escalating the severity of disciplinary responses. Teachers read two office discipline referrals for a student that occurred over the span of three days. The name of the disciplined student was either stereotypically Black (e.g., "Darnell”) or stereotypically White (e.g., "Greg”). Teachers felt more troubled (e.g., hindered from maintaining control) and endorsed more severe 
discipline if the student was Black, as compared to White, which escalated more quickly for Black students over time.

\section{Context}

Experimental research indicates that context can shape the connection between a target's social identity and responses to it, such as expectations of children in school. For instance, Darley and Gross (1983) manipulated context by randomly assigning participants to view video of a child in different environments. Participants reported lower expectations for the child if the video contained scenes of an urban school and neighborhood with run-down two-family homes, as compared to a suburban school and neighborhood with five- and six-bedroom homes. Amid the COVID-19 pandemic, distance learning changes the context wherein educators perceive children and their behaviors, and therefore may affect discipline.

\section{Fear}

Fear can be a key factor in providers' decision-making about preschool expulsion. Gilliam and Reyes' (2018) measurement validation study, for example, found that teachers' fear of accountability for safety was the strongest predictor of a child's probability of expulsion. Additionally, fear is prominent amid COVID-19. Public fears of infectious diseases are associated with varied psychosocial consequences, including denial, loss, stigmatization, and discrimination toward marginalized or minoritized populations (see Pappas et al., 2009 for review). The Centers for Disease Control and Prevention (CDC) have issued ongoing guidance to early childhood education providers to support safety, coping, and resilience in their classrooms (CDC, 2021). Providers' fears in the context of COVID-19 may add complexity to the association between fear and discipline in early childhood education settings.

\section{Current Research}


Extending previous literature, the current study focused singularly on hypothetical vignettes about a Black boy's behaviors to investigate the effects of the pandemic (i.e. distance learning context and fears of COVID-19) on preschool providers' responses to behaviors and discipline decisions. We tested three hypotheses. (1) Replicating previous scholarship, we expected that providers would feel more troubled and endorse more severe discipline over the course of three vignettes about a Black boy's behaviors. (2) We expected that providers would feel more troubled and endorse more severe discipline in a distance learning context, as compared to an in-person context. (3) We expected that providers' fears of COVID-19 would account for their feeling more troubled and endorsements of discipline.

\section{Method}

\section{Participants and Sampling Procedure}

Participants included 60 preschool providers from one large school district in a large city in a West Coast state. According to the most recent publicly available data reported to the state before COVID-19, the district served a K-12 student body of nearly 50,000 students that was approximately $24 \%$ Black and 10\% White, with more than two-thirds of students qualified for free or reduced-price meals. ${ }^{2}$ The majority of participants who reported demographic information were racially/ethnically minoritized and/or multiracial (83\%), female (89\%), and teachers (77\%), with diverse educational attainment and years of experience. Between-subjects $t$-tests and chisquare analyses indicated there were no significant differences between participant demographics by condition. A detailed description of the demographic data and variable coding is included in Table 1 and the Supplemental Materials, respectively.

To meet inclusion criteria, all participants had to be district employees who worked professionally in early childhood education programs in the district. The population included 190 
providers based on a roster provided by the school district. Our recruitment aims were modest due to the pandemic. Following the protocol approved by the Institutional Review Board (IRB), the research team provided the district administration with a template message and links to recruit providers by email to participate in an online survey. Initially, only preschool teachers were recruited. However, to include as diverse of a sample of early childhood education professionals as possible, the district leadership advised expanding recruitment efforts after the study had launched to include all early education professionals working in the district (e.g., assistant teachers). The survey was open to participation for 36 days between September October, 2020. The school district conducted one professional development training during the study (at an approximate study midpoint), when the pool of possible participants was reminded by district leadership about the invitation to participate in the study. Informed consent was obtained from all participants. Participants completed the survey at their convenience during the study period. The participant flow is further detailed in the Supplemental Materials.

During the study, all participants were working remotely and the district was using distance learning across all preschool sites. We stopped data collection when all who were willing to consent participated in the study. Each participant received a \$15 gift card after participation. No consenting participants who completed the survey and recorded any response were excluded from analyses. All results presented in the current study were based on data from one survey.

Per guidance from the IRB, participants were not forced to respond to any outcome questions. Thus, for some outcomes the sample size varies due to participant non-response. See Table 1 for details about missing data for the full sample and by experimental condition for feeling troubled, discipline severity, the FCV-19S, and demographic information. A chi-square 
test of independence examining the relation between condition and a dichotomous missing data variable $(0=$ complete data, $1=$ any instance of missing data $)$ showed that there was no significant relation between condition and the missing data for the repeated measures of feeling troubled, discipline severity, and the FCV-19S. Participants in either condition were no more or less likely to have complete or missing data for the primary outcomes and the FCV-19S. Missing data were excluded from analyses such that data was not imputed for the item with missing data, but a participant's other data was maintained in analyses, including aggregated variables.

\section{Measures}

\section{Feeling Troubled}

We used the same items for the feeling troubled scale as used in previous research by Okonofua and Eberhardt (2015). Participants completed this scale after each vignette, three times total per participant. Participants were asked to indicate their responses to the following items on 5-point Likert scales: "How severe is Terrell's behavior?" $(1=$ Not at all severe, $5=$ Extremely severe); "To what extent is Terrell hindering you from maintaining order in the class?" $(1=$ Not at all hindering, 5 = Extremely hindering); and "How irritating is Terrell?" $(1=$ Not at all irritating, 5 = Extremely irritating). Consistent with previous research, the overall score for feeling troubled was derived by averaging participants' responses to the scales after each vignette, $\alpha_{1}=.83, M_{1}=1.89 S D_{1}=.89 ; \alpha_{2}=.91, M_{2}=2.34, S D_{2}=1.02 ; \alpha_{3}=.94, M_{3}=2.52, S D_{3}$ $=1.04$.

\section{Discipline Severity}

We used the same single-item measure for discipline severity as used in previous research by Okonofua and Eberhardt (2015). The item asked participants to indicate on a 5-point Likert scale how severely they thought the child should be disciplined. Participants were asked, "How 
severely should Terrell be disciplined?" $(1=$ Not at all severe, $5=$ Extremely severe $)$.

Participants completed this item after they read each vignette, three times total per participant, $M_{1}=1.31, S D_{1}=0.70 ; M_{2}=1.62, S D_{2}=0.70 ; M_{3}=1.75, S D_{3}=0.93$.

\section{Fear of COVID-19 Scale}

The Fear of COVID-19 Scale (FCV-19S; Ahorsu et al., 2020) is a seven-item scale that asks participants to indicate their level of agreement with statements such as, "I am afraid of losing my life because of coronavirus-19" and "I cannot sleep because I am worrying about getting coronavirus-19," on a 5-point rating scale ( 1 = Strongly disagree, $5=$ Strongly agree $)$.

The FCV-19S has robust psychometric properties to assess fear of COVID-19 among the general population (Ahorsu et al., 2020). Summing scores for each item produces the overall score, such that a higher score indicates greater fear. To cohere with our analytic plan for other measures, we computed an overall score for fear of COVID-19 by averaging each participant's responses to the FCV-19S, $\alpha=.92, M=2.73, S D=1.03$. Models run with summed and averaged scores were consistent (see the Supplemental Materials), and thus we report findings based on average scores.

\section{Design}

We used a survey platform to randomly assign participants to one of two betweensubjects conditions (distance learning or in-person classroom context) for three vignettes. Participants were not notified about the existence of an alternate context. All participants read vignettes and completed survey items in the same order. The experimental manipulations for each study condition involved using text descriptions (e.g., "a virtual classroom for distance learning”) and images (e.g., a computer, keyboard, and speakers on a desk) to stimulate the classroom context. 
Participants read three vignettes about a Black boy's behaviors, which were shown one at a time and described as consecutive over the course of three days. Vignettes were selected from a library of 23 researcher-generated scenarios based on child behaviors perceived as challenging in early care settings (see Schwarzwalter \& Danielson, 2008) and previous research examining whether racial stereotypes influence teachers' disciplinary responses over the course of multiple incidents (see Okonofua \& Eberhardt, 2015). The vignettes (1) quiet, (2) playing, and (3) circle were selected because they captured a range of early childhood behaviors and suited in-person and distance learning contexts (see Table 2). Similar to previous research (e.g., Jarvis \& Okonofua, 2020; Okonofua \& Eberhardt, 2015; Okonofua et al., 2020), the boy's race was indicated using a stereotypically Black male name (e.g., “Terrell”; see Greenwald et al., 1998).

\section{Procedure}

First, depending on condition, participants were asked to imagine themselves as a prekindergarten teacher managing a virtual classroom or a typical (in-person) classroom where they took part in disciplining a student. Next, participants read three vignettes about the same Black boy. After each vignette, participants responded to the feeling troubled and discipline severity primary outcome measures. Participants then completed the FCV-19S (Ahorsu et al., 2020) and other non-repeated measures (see the Supplemental Materials for additional measures).

\section{Analytic Strategy}

To test for an escalation effect such that the context condition interacts with time, models for primary outcomes included repeated measures for responses to each of the vignettes. Given the longitudinal nature of the data, Akiake information criterion (AIC; Akiake, 1974) model comparisons were employed to strategically determine the model to best fit the data. We 
followed the recommendation of Liu and colleagues (2012) to take a data-driven approach that compares model AICs between growth, covariance pattern, and repeated measures ANOVA model specifications. The models were run in the R-programming language using the package "nlme" version 3.1-148. The mixed effects quadratic growth model was the best fit to the data for the primary outcomes, feeling troubled and discipline severity. The outcome variables were modeled as a function of the interaction between condition (effect coded: $-0.5=$ distance learning, $0.5=$ in-person) and the linear and quadratic effects of time with random intercepts and random linear slopes for time for each participant. The effect of classroom context on each outcome was robust and remained significant with relevant covariates added to the models. Additionally, linear growth models were the best fit for effects of fear of COVID-19 on feeling troubled and discipline severity. See Tables S3-S6 in the Supplemental Materials.

Next, linear mixed models treated with random intercepts were used to determine a potential effect of classroom context specific to individual vignettes. We created a dummy variable for the second vignette (playing) and a dummy variable for the third vignette (circle), leaving the first vignette (quiet) as the baseline. The variables were coded such that $1=$ the vignette, $0=$ not the vignette. Our outcome variables were modeled as a function of the interactions between the classroom context condition (effect coded: $-0.5=$ distance learning, 0.5 = in-person) and its interactions with the vignette dummy variables with random intercepts for each participant.

\section{Results}

\section{Feeling Troubled}

The mixed effects quadratic growth model for feeling troubled revealed a significant linear effect of time such that providers felt more troubled as vignettes progressed, $b=0.53, S E$ 
$=0.14, t(100)=3.81, p<.001,95 \% C I[0.26,0.81]$, and a non-significant quadratic effect of time, $b=-0.11, S E=0.06, t(100)=-1.65, p=.102,95 \% C I[-0.23,0.02]$. While there was no main effect of classroom context, $b=0.121, S E=0.24, t(54)=0.50, p=.621,95 \% C I[-0.36$, $0.60]$, there was a significant interaction of classroom context and time (linear: $b=-0.96, S E=$ $0.28, t(100)=-3.42, p<.001,95 \% C I[-1.51,-41]$; quadratic: $b=0.42, S E=0.13, t(100)=3.30$, $p=.001,95 \% C I[0.17,0.68])$. A distance learning context, as compared to in-person, led participants to feel more troubled for the second and third vignettes. See Table 3 and Figure 1, panel A for a summary of the effects.

Effects on feeling troubled varied by vignette. Linear mixed models of classroom context and dummy variables for vignettes, with random intercepts for participants, revealed a main effect of the playing vignette, $b=0.43, S E=0.10, t(101)=4.46, p<.001,95 \% C I[0.24,0.62]$, and the circle vignette, $b=0.64, S E=0.10, t(102)=6.47, p<.001,95 \% C I[0.45,0.83]$, such that providers felt more troubled after these vignettes than after the baseline vignette. There was not a main effect of classroom context, $b=0.13, S E=0.26, t(77)=0.48, p=.633,95 \% C I[-$ $0.39,0.64]$. There was a significant interaction of classroom context and the playing vignette, $b=$ $-0.54, S E=0.19, t(101)=-2.80, p=.006,95 \% C I[-0.92,-0.16]$. Though in the expected direction, there was not a significant interaction between classroom context and the circle vignette, $b=-0.25, S E=0.19, t(102)=-1.27, p=.207,95 \% C I[-0.64,0.14]$ (see Supplemental Materials Table S11).

\section{Discipline Severity}

The mixed effects quadratic growth model for discipline severity revealed a significant linear effect of time, $b=0.48, S E=0.13, t(98)=3.63, p<.001,95 \% C I[0.22,0.73]$, and quadratic effect of time, $b=-0.12, S E=0.06, t(98)=-2, p=.05,95 \% C I[-0.23,-0.002]$, such 
that endorsements of discipline severity increased over time. While there was no main effect of classroom context, $b=-0.02, S E=0.21, t(51)=-0.10, p=0.92,95 \% C I[-0.44,0.40]$, there were significant interactions of classroom context and time (linear: $b=-0.74, S E=0.26, t(98)=-2.84$, $p=.005,95 \% C I[-1.26,-0.23]$; quadratic: $b=0.31, S E=0.12, t(98)=2.64, p=.01,95 \% C I$ $[0.08,0.54]$. A distance learning context, as compared to in-person, led participants to show a sharper escalation in the severity of discipline they endorsed as a function of the vignette. See Table 4 and Figure 1, panel B for a summary of the effects.

Effects on discipline severity varied by vignette. Linear mixed models of classroom context condition and dummy variables for vignettes, with random intercepts for participants, revealed a main effect of the playing vignette, $b=0.36, S E=0.10, t(98)=3.75, p<.001,95 \%$ $C I[0.17,0.55]$, and the circle vignette, $b=0.50, S E=0.10, t(98)=5.15, p<.001,95 \% C I[0.50$, 0.69], such that providers endorsed more severe discipline after these vignettes than after the baseline vignette. There was not a main effect of classroom context, $b=-0.02, S E=0.24, t(79)=$ $-0.07, p=.942,95 \% C I[-0.48,0.45]$. Though in the expected direction, there was not a significant interaction between classroom context and the circle vignette, $b=-0.24, S E=0.20$, $t(98)=-1.25, p=.215,95 \% C I[-0.62,0.14]$. There was a significant interaction of classroom context and the playing vignette, $b=-0.44, S E=0.20, t(98)=-2.26, p=.026,95 \% C I[-0.81,-$ 0.06] (see Supplemental Materials Table S11).

\section{Fears of COVID-19}

We were also interested in the effect of providers' fears of COVID-19 on the primary outcomes. A linear growth model treated with random effects for subject intercepts and linear effects of time (subject-level) while controlling for experimental condition revealed a significant effect of fear of COVID-19 on feeling troubled, $b=0.42, S E=0.12, t(44)=3.55, p<.001,95 \%$ 
$C I[0.19,0.65]$, and an effect on discipline severity that approached significance, $b=0.19, S E=$ $0.10, t(44)=1.88, p=.07,95 \% C I[-0.01,0.40]$. The more providers feared COVID-19, the more troubled they felt in response to the child's behaviors (see Tables S7, S8 and Figures S3, S4 in the Supplemental Materials).

\section{Discussion}

This is the first experimental study to examine whether preschool providers' disciplinary responses to a Black boy's behaviors vary by classroom context. We found support for our hypothesis predicting (1) there would be an escalation in providers' troubled feelings and endorsements of discipline over the course of three hypothetical vignettes about a Black boy's behaviors. Additionally, the results are consistent with our hypotheses predicting (2) providers would feel more troubled and endorse more severe discipline in a distance learning context, as compared to an in-person context; and (3) providers' fears of COVID-19 would account for their feeling troubled and discipline severity.

Although there was not a main effect of classroom context on the extent participants felt troubled or endorsed severe discipline, there was a significant effect of the interaction between classroom context and time on the primary outcomes. The distance learning context, as compared to in-person, led participants to show heightened troubled feelings and endorsements of discipline over the course of three vignettes. Previous theory suggests that both time and context matter for the disciplining of Black children (Okonofua et al., 2016). Namely, effects of degree of racial salience and/or stereotypicality on punitiveness is a process that develops over the course of multiple incidents. Stereotypes can stitch together otherwise unrelated incidents into a problematic pattern, eliciting a more severe response. Separate research suggests that context can guide interpretation of ambiguous behavior (e.g., Correll et al., 2011; Darley \& 
Gross, 1983). The present research provides empirical evidence that context can interact with psychological processes based on a target's race, which develop over time.

Findings about fear and feeling troubled also provide key insights. The more that participants feared COVID-19, the more troubled they felt by the Black boy over the sequence of vignettes across conditions. Additionally, the more participants feared COVID-19, the more their responses to the boy's behaviors trended toward more severe endorsements of discipline over the course of vignettes. This is consistent with previous research reporting an association between fear and aggression (e.g., Mifune et al., 2017). The present findings suggest that fears specific to the COVID-19 pandemic can translate to distress in pivotal teacher-child exchanges. Future empirical research should investigate processes by which preschool providers' specific fears affect their decision-making and responses to young children.

\section{Limitations}

We discuss four important limitations to this research and suggest how they may be addressed in future work. First, though we found significant effects of time, it is possible that the vignettes systematically differed in perceived severity. The playing vignette, in particular, led providers to feel more troubled and to desire heightened discipline severity in a distance learning context, as compared to an in-person context. We speculate that because playing featured a Black boy displaying externalizing behaviors when he "runs around the room," providers' disciplinary responses may have been especially activated compared to the behaviors in the quiet and circle vignettes. This rationale is consistent with nationally representative evidence indicating that teachers perceive that Black boys in kindergarten have more problematic externalizing behaviors and issues with attentional focus and inhibitory control compared to their peers, which may set 
them up for fraught relationships with teachers and disproportionate school discipline (Wood et al., 2017). Future research should test that the escalation effect is robust to scenario order.

Second, findings from this research are limited by the size of the sample. Future experiments should test the generalizability of these findings with larger samples including preschool providers from diverse school districts across the country (e.g., nationally representative sample). To help avoid attrition, future studies may consider increasing the compensation for participation.

Third, the present research relied on a single repeated item to measure the severity of teachers' responses to each vignette. Future research could benefit from the addition of more repeated discipline items to better understand discipline effects and how they develop — or notover time. This could include quantitative measures of specific disciplinary actions (e.g., likelihood of personal disciplinary actions versus referrals to a principal) and qualitative measures (e.g., open-ended questions about how and why teachers would respond to each vignette).

Lastly, the current study did not examine the influence of stereotypes or intersections among them (e.g., race and gender) on school discipline outcomes. Future studies with larger samples are needed to examine how classroom context, fears of COVID-19, and stereotypes account for preschool providers' differential disciplinary responses to diverse children over the course of multiple vignettes.

\section{Implications for Practice}

The results from our study cohere with K-12 research indicating that context matters in relation to school discipline outcomes, especially for Black boys. Amid the COVID-19 
pandemic - and beyond - this research highlights pressing next steps for school psychologists, mental health consultants, and other professionals in early education.

First, the results resonate with literature indicating the importance of the student-teacher relationship to mitigating discipline outcomes (Okonofua et al., 2016; Wood et al., 2017). The pandemic revealed that distance learning presents new constraints and opportunities for providers to build relationships with children and families through virtual platforms. From the lens of Bowlby's (1982) attachment theory, we surmise that the provider who maintains proximity and is responsive and available to a child's needs, rather than exclusionary, can better support a child's learning and exploration during the critical preschool years. We therefore recommend that practitioners employ strategic, scalable, and potentially integrated approaches that focus on reducing exclusionary discipline by enhancing teacher-student relationships. Research suggests this can be accomplished by way of skill-building (Gregory et al., 2016), mindsets (Okonofua et al., 2016), and implementation-based state-level policy initiatives (e.g., the Pyramid Model; see, for example, Vinh et al., 2016). Finding effective ways to adapt strategies and connect on virtual platforms is especially important during the pandemic because the quality of early teacher-child relationships predicts adjustment and relationships in elementary school (Pianta et al., 1995).

Second, the results from this study can inform preservice teacher training and in-service professional development efforts. Such efforts may focus on building equitable and inclusive pedagogies, curricula, and climates that address ecological, intersecting oppressions (Annamma \& Morrison, 2018) and support providers' engagement with diverse children and families. Further, inclusion-focused coaching, consultation, and advocacy will be crucial to disrupting extant racial disparities in discipline. When integrated with critical theoretical perspectives such 
as DisCrit, the evidence may help shift dialogue away from disordered and disorderly individual behaviors, toward ecological educational transformations (Annamma et al., 2013; Annamma \& Morrison, 2018). Such transformations should emerge from providers' lived experiences and include classrooms that flexibly accommodate and include all children and families.

Finally, practitioners should work in collaboration with school site teams to reflexively examine preschool providers' perspectives on discipline during distance learning and in-person instruction. This requires facilitating consultation about fears, distress, and child behaviors. Such sessions, while triggered by the extraordinary context of the pandemic, distance learning, and equity concerns, may lend to more inclusive pedagogies and new approaches to developmentally appropriate practice (Copple \& Bredekamp, 2009), even post-pandemic. School psychologists and allied professionals are critically positioned to carry out evidence-informed consultative interventions in preschools, supporting providers and contributing to a better start for all children in-person and from a distance. 


\section{References}

Ahorsu, D. K., Lin, C. Y., Imani, V., Saffari, M., Griffiths, M. D., \& Pakpour, A. H. (2020). The Fear of COVID-19 Scale: Development and initial validation. International Journal of Mental Health and Addiction, 36(3), 159-164. https://doi.org/10.1007/s11469-020$00270-8$

Akaike, H. (1974). A new look at the statistical model identification. IEEE Transactions on Automatic Control, 19(6), 716-723. https://doi.org/10.1109/TAC.1974.1100705

Annamma, S. A., Connor, D., \& Ferri, B. (2013). Dis/ability critical race studies (DisCrit): Theorizing at the intersections of race and dis/ability. Race Ethnicity and Education, 16(1), 1-31. https://doi.org/10.1080/13613324.2012.730511

Annamma, S., \& Morrison, D. (2018). DisCrit Classroom Ecology: Using praxis to dismantle dysfunctional education ecologies. Teaching and Teacher Education, 73, 70-80. https://doi.org/10.1016/j.tate.2018.03.008

Barnes, J. C., \& Motz, R. T. (2018). Reducing racial inequalities in adulthood arrest by reducing inequalities in school discipline: Evidence from the school-to-prison pipeline. Developmental Psychology, 54(12), 2328-2340. https://doi.org/10.1037/dev0000613

Barnett, W. S. (2011). Effectiveness of early educational intervention. Science, 333(6045), 975978. https://doi.org/10.1126/science.1204534

Barnett, W. S. (1998). Long-term cognitive and academic effects of early childhood education on children in poverty. Preventive Medicine, 27(2), 204-207. https://doi.org/10.1006/pmed.1998.0275 
Boutte, G., \& Bryan, N. (2019). When will Black children be well? Interrupting anti-Black violence in early childhood classrooms and schools. Contemporary Issues in Early Childhood, 1-19. https://doi.org/10.1177/1463949119890598

Bowlby, J. (1982). Attachment and loss: Volume I: Attachment (2nd ed.). New York: Basic Books.

Centers for Disease Control and Prevention. (2021, June 10). Guidance for operating child care programs during COVID-19. https://www.cdc.gov/coronavirus/2019ncov/community/schools-childcare/guidance-for-childcare.html

Copple, C., \& Bredekamp, S. (Eds.). (2009). Developmentally appropriate practice in early childhood programs serving children from birth through age 8 (3rd ed.). Washington, DC: National Association for the Education of Young Children.

Correll, J., Wittenbrink, B., Park, B., Judd, C. M., \& Goyle, A. (2011). Dangerous enough: Moderating racial bias with contextual threat cues. Journal of Experimental Social Psychology, 47(1), 184-189. https://doi.org/10.1016/j.jesp.2010.08.017

Darley, J. M., \& Gross, P. H. (1983). A hypothesis-confirming bias in labeling effects. Journal of Personality and Social Psychology, 44(1), 20-33. https://doi.org/10.1037/00223514.44 .1 .20

Eberhardt, J. L., Davies, P. G., Purdie-Vaughns, V. J., \& Lynn Johnson, S. (2006). Looking deathworthy: Perceived stereotypicality of Black defendants predicts capital-sentencing outcomes. Psychological Science, 17(5), 383-386. https://doi.org/10.1111/j.14679280.2006.01716.x

Gilliam, W. S. (2005). Prekindergarteners left behind: Expulsion rates in state prekindergarten systems. 
https://medicine.yale.edu/childstudy/policy/Images/National\%20Prek\%20Study_expulsio n_tcm942-34954.pdf

Gilliam, W. S., Maupin, A. N., Reyes, C. R., Accavitti, M., \& Shic, F. (2016). Do early educators' implicit biases regarding sex and race relate to behavior expectations and recommendations of preschool expulsions and suspensions? https://medicine.yale.edu/childstudy/zigler/publications/Preschool\%20Implicit\%20Bias\% 20Policy\%20Brief_final_9_26_276766_5379_v1.pdf

Gilliam, W. S., \& Reyes, C. R. (2018). Teacher decision factors that lead to preschool expulsion: Scale development and preliminary validation of the Preschool Expulsion Risk Measure. Infants and Young Children, 31(2), 91-106.

https://doi.org/10.1097/IYC.0000000000000113

Gilliam, W. S., \& Shahar, G. (2006). Preschool and child care expulsion and suspension: Rates and predictors in one state. Infants and Young Children, 19(3), 228-245. https://doi.org/10.1097/00001163-200607000-00007

Girvan, E. J., Gion, C., McIntosh, K., \& Smolkowski, K. (2016). The relative contribution of subjective office referrals to racial disproportionality in school discipline. School Psychology Quarterly, 32(3), 392-404. https://doi.org/10.1037/spq0000178

Goff, P. A., Jackson, M. C., Di Leone, B. A. L., Culotta, C. M., \& DiTomasso, N. A. (2014). The essence of innocence: Consequences of dehumanizing black children. Journal of Personality and Social Psychology, 106(4), 526-545. https://doi.org/10.1037/a0035663

Greenwald, A. G., McGhee, D. E., \& Schwartz, J. L. K. (1998). Measuring individual differences in implicit cognition: The implicit association test. Journal of Personality and Social Psychology, 74(6), 1464-1480. https://doi.org/10.1037/0022-3514.74.6.1464 
Gregory, A., Hafen, C. A., Ruzek, E., Mikami, A. Y., Allen, J. P., \& Pianta, R. C. (2016). Closing the racial discipline gap in classrooms by changing teacher practice. School Psychology Review, 45(2), 171-191. https://doi.org/10.17105/SPR45-2.171-191

Gregory, A., Skiba, R. J., \& Noguera, P. A. (2010). The achievement gap and the discipline gap: Two sides of the same coin? Educational Researcher, 39(1), 59-68. https://doi.org/10.3102/0013189X09357621

Hannon, L., DeFina, R., \& Bruch, S. (2013). The relationship between skin tone and school suspension for African Americans. Race and Social Problems, 5(4), 281-295. https://doi.org/10.1007/s12552-013-9104-z

Jackson, D., Testa, A., Todić, J., \& Leos-Martinez, J. (2021). Exclusionary school discipline during childhood and adolescent police encounters. Deviant Behavior, 1-20. https://doi.org/10.1080/01639625.2021.1891843

Jarvis, S. N., \& Okonofua, J. A. (2020). School deferred: When bias affects school leaders. Social Psychological and Personality Science, 11(4), 492-498. https://doi.org/10.1177/1948550619875150

Lewis, C. W., Butler, B. R., Bonner, F. A., \& Joubert, M. (2010). African American male discipline patterns and school district responses resulting impact on academic achievement: Implications for urban educators and policy makers. Journal of African American Males in Education, 1(1), 7-25.

Liu, S., Rovine, M. J., \& Molenaar, P. C. M. (2012). Selecting a linear mixed model for longitudinal data: Repeated measures analysis of variance, covariance pattern model, and growth curve approaches. Psychological Methods, 17(1), 15-30.

https://doi.org/10.1037/a0026971 
Losen, D. J., \& Whitaker, A. (2018). 11 million days lost: Race, discipline, and safety at U.S. public schools. https://www.aclu.org/sites/default/files/field_document/final_11-milliondays_ucla_aclu.pdf

Martin, K. A., Bosk, E., \& Bailey, D. (2018). Teachers' perceptions of childcare and preschool expulsion. Children and Society, 32(2), 87-97. https://doi.org/10.1111/chso.12228

Mifune, N., Simunovic, D., \& Yamagishi, T. (2017). Intergroup biases in fear-induced aggression. Frontiers in Psychology, 8(49), 1-9. https://doi.org/10.3389/fpsyg.2017.00049

Monroe, C. R. (2005). Why are "bad boys" always Black?: Causes of disproportionality in school discipline and recommendations for change. Journal of Educational Strategies, Issues and Ideas, 79(1), 45-50. https://doi.org/10.3200/TCHS.79.1.45-50

Mueller, J. T., McConnell, K., Burow, P. B., Pofahl, K., Merdjanoff, A. A., \& Farrell, J. (2020). Impacts of the COVID-19 pandemic on rural America. Proceedings of the National Academy of Sciences of the United States of America, 118(1), 1-6. https://doi.org/10.1073/pnas.2019378118

Okonofua, J. A., Perez, A. D., \& Darling-Hammond, S. (2020). When policy and psychology meet: Mitigating the consequences of bias in schools. Science Advances, 6(42), 110. https://doi.org/10.1126/sciadv.aba9479

Okonofua, J. A., \& Eberhardt, J. L. (2015). Two strikes: Race and the disciplining of young students. Psychological Science, 26(5), 617-624. https://doi.org/10.1177/0956797615570365

Okonofua, J. A., Paunesku, D., \& Walton, G. M. (2016). Brief intervention to encourage empathic discipline cuts suspension rates in half among adolescents. Proceedings of the 
National Academy of Sciences of the United States of America, 113(19), 5221-5226. https://doi.org/10.1073/pnas.1523698113

Pappas, G., Kiriaze, I. J., Giannakis, P., \& Falagas, M. E. (2009). Psychosocial consequences of infectious diseases. Clinical Microbiology and Infection, 15(8), 743-747. https://doi.org/10.1111/j.1469-0691.2009.02947.x

Pianta, R. C., Barnett, W. S., Burchinal, M., \& Thornburg, K. R. (2009). The effects of preschool education: What we know, how public policy is or is not aligned with the evidence base, and what we need to know. Psychological Science in the Public Interest, 10(2), 49-88. https://doi.org/10.1177/1529100610381908

Pianta, R. C., Steinberg, M. S., \& Rollins, K. B. (1995). The first two years of school: Teacherchild relationships and deflections in children's classroom adjustment. Development and Psychopathology, 7(2), 295-312. https://doi.org/10.1017/S0954579400006519

Prime, H., Wade, M., \& Browne, D. T. (2020). Risk and resilience in family well-being during the COVID-19 pandemic. American Psychologist, 75(5), 631-643. https://doi.org/10.1037/amp0000660

Quandt, S. A., LaMonto, N. J., Mora, D. C., Talton, J. W., Laurienti, P. J., \& Arcury, T. A. (2021). COVID-19 pandemic among Immigrant Latinx farmworker and non-farmworker families: A rural-urban comparison of economic, educational, healthcare, and immigration concerns. New Solutions, 31(1), 30-47. https://doi.org/10.1177/1048291121992468

Schwarzwalter, K., \& Danielson, R. (2008). Licensed child care dismissal study. North Dakota State Data Center - North Dakota State University. 
https://www.ndsu.edu/sdc/publications/reports/LicensedChildCareDismissalStudy_Final Results.pdf

Silverman, M., Sibbald, R., \& Stranges, S. (2020). Ethics of COVID-19-related school closures. Canadian Journal of Public Health, 111(4), 462-465. https://doi.org/10.17269/s41997020-00396-1

Skiba, R. J., Chung, C.-G., Trachok, M., Baker, T. L., Sheya, A., \& Hughes, R. L. (2014). Parsing disciplinary disproportionality: Contributions of infraction, student, and school characteristics to out-of-school suspension and expulsion. American Educational Research Journal, 51(4), 640-670. https://doi.org/10.3102/0002831214541670

United States Department of Education. (2021). 2017-2018 Civil Rights Data Collection (Updated May 10, 2021) [Suspensions.csv]. Office for Civil Rights. https://www2.ed.gov/about/offices/list/ocr/docs/2017-18-crdc-data.zip

Vinh, M., Strain, P., Davidon, S., \& Smith, B. J. (2016). One state's systems change efforts to reduce child care expulsion: Taking the Pyramid Model to scale. Topics in Early Childhood Special Education, 36(3), 159-164. https://doi.org/10.1177/0271121415626130

Welsh, R. O., \& Little, S. (2018). The school discipline dilemma: A comprehensive review of disparities and alternative approaches. Review of Educational Research, 88(5), 752-794. https://doi.org/10.3102/0034654318791582

Wood, J. L., Blevins, D., \& Essien, I. (2017). Black males in kindergarten: The effect of social skills on close and conflictual relationships with teachers. Journal of African American Males in Education Fall, 8(2), 30-50. 
Yoshikawa, H., Weiland, C., Brooks-Gunn, J., Burchinal, M. R., Espinosa, L. M., Gormley, W. T., Ludwig, J., Magnuson, K., Phillips, D., \& Zaslow, M. J. (2013). Investing in our future: The evidence base on preschool education. The Foundation for Child Development. https://www.fcd-us.org/assets/2016/04/Evidence-Base-on-PreschoolEducation-FINAL.pdf 


\section{Footnotes}

${ }^{1}$ These numbers were calculated using 2017-2018 Civil Rights Data Collection public-use survey data (updated May 10, 2021) downloaded from the United States Department of Education Office for Civil Rights.

${ }^{2}$ District enrollment estimates were calculated using publicly-available data from the state Department of Education for the 2018-2019 school year. 


\section{Table 1}

Descriptive statistics and between-subjects tests on demographic variables and missing data

\begin{tabular}{|c|c|c|c|c|c|}
\hline Variable & Category & Full Sample & $\begin{array}{l}\frac{\text { Condition }}{\text { Distance }} \\
\text { Learning }\end{array}$ & In-Person & Statistical Test \\
\hline Missing data & $\begin{array}{l}\text { Percent missing a } \\
\text { response for }>1 \\
\text { survey item }\end{array}$ & $60 \%(n=36 / 60)$ & $63 \%$ & $57 \%$ & $\begin{array}{l}\text { Missing data: } \chi^{2}(1)= \\
0.07, p=.79\end{array}$ \\
\hline $\begin{array}{l}\text { Missing data for } \\
\text { feeling troubled } \\
\text { (vignettes } 1-3 \text { ) }\end{array}$ & $\begin{array}{l}\text { Percent missing a } \\
\text { response for }>1 \\
\text { survey item }\end{array}$ & $17 \%(n=10 / 60)$ & $23 \%$ & $10 \%$ & $\begin{array}{l}\text { Missing data: } \chi^{2}(1)= \\
1.08, p=.299\end{array}$ \\
\hline $\begin{array}{l}\text { Missing data for } \\
\text { discipline severity } \\
\text { (vignettes 1-3) }\end{array}$ & $\begin{array}{l}\text { Percent missing a } \\
\text { response for }>1 \\
\text { survey item }\end{array}$ & $17 \%(n=10 / 60)$ & $23 \%$ & $10 \%$ & $\begin{array}{l}\text { Missing data: } \chi^{2}(1)= \\
1.08, p=.299\end{array}$ \\
\hline $\begin{array}{l}\text { Missing data for fear } \\
\text { of COVID-19 } \\
\text { (average) }\end{array}$ & $\begin{array}{l}\text { Percent missing a } \\
\text { score for the scale }\end{array}$ & $22 \%(n=13 / 60)$ & $27 \%$ & $17 \%$ & $\begin{array}{l}\text { Missing data: } \chi^{2}(1)= \\
0.39, p=.531\end{array}$ \\
\hline $\begin{array}{l}\text { Baseline feeling } \\
\text { troubled score } \\
\text { (vignette } 1 \text { ) }\end{array}$ & & $M=1.89$ & $M=1.81$ & $M=1.97$ & $\begin{array}{l}\text { Feeling troubled: } t(53) \\
=-0.63, p=.53\end{array}$ \\
\hline $\begin{array}{l}\text { Baseline discipline } \\
\text { severity score } \\
\text { (vignette } 1 \text { ) }\end{array}$ & & $M=1.31$ & $M=1.33$ & $M=1.29$ & $\begin{array}{l}\text { Discipline severity: } \\
t(50)=0.24, p=.81\end{array}$ \\
\hline
\end{tabular}




\begin{tabular}{|c|c|c|c|c|c|c|}
\hline Variable & Category & Full Sample & Condition & & Statistical Test & \\
\hline & & & & & $\underline{\text { Recoded variable }}$ & $\underline{\text { Original variable }}$ \\
\hline Race & $\begin{array}{l}\text { All other races and/or } \\
\text { combination of races }\end{array}$ & $83 \%(n=39 / 47)$ & $82 \%$ & $84 \%$ & & $\begin{array}{l}\text { All races: } \\
\chi^{2}(1)=0, p=1\end{array}$ \\
\hline Age & $18-40$ years old & $24 \%(n=11 / 46)$ & $29 \%$ & $20 \%$ & $\chi^{2}(1)=0.11, p=.740$ & $\chi^{2}(3)=4.55, p=.208$ \\
\hline Gender & Female & $89 \%(n=40 / 45)$ & $86 \%$ & $92 \%$ & & $\chi^{2}(1)=0.03, p=.874$ \\
\hline \multirow[t]{3}{*}{ Education } & Bachelor's degree & $25 \%(n=11 / 45)$ & $50 \%$ & $28 \%$ & $\chi^{2}(2)=2.30, p=.32$ & $\chi^{2}(3)=2.34, p=.505$ \\
\hline & Master's degree & $38 \%(n=17 / 45$ & $30 \%$ & $44 \%$ & & \\
\hline & Other degree & $38 \%(n=17 / 45)$ & $20 \%$ & $28 \%$ & & \\
\hline \multirow[t]{3}{*}{ Job Title } & Teacher & $43 \%(n=20 / 47)$ & $50 \%$ & $36 \%$ & $\chi^{2}(2)=2.36, p=.307$ & $\chi^{2}(3)=2.60, p=.457$ \\
\hline & Master Teacher & $34 \%(n=16 / 47)$ & $23 \%$ & $44 \%$ & & \\
\hline & Other & $23 \%(n=11 / 47$ & $27 \%$ & $20 \%$ & & \\
\hline $\begin{array}{l}\text { First Generation } \\
\text { College Graduate }\end{array}$ & No & $54 \%(n=25 / 46)$ & $38 \%$ & $68 \%$ & & $\chi^{2}(1)=2.99, p=.08$ \\
\hline
\end{tabular}




\begin{tabular}{|c|c|c|c|c|c|c|}
\hline Variable & Category & Full Sample & $\begin{array}{l}\text { Condition } \\
\text { Distance } \\
\text { Learning }\end{array}$ & In-Person & Statistical Test & \\
\hline Salary & & & & & & $\chi^{2}(3)=2.89, p=.408$ \\
\hline Years Teaching & Less than 10 years & $26 \%(n=12 / 47)$ & $18 \%$ & $32 \%$ & $\chi^{2}(1)=0.56, p=.454$ & $\chi^{2}(3)=3.86, p=.277$ \\
\hline \multirow{3}{*}{$\begin{array}{l}\text { Years Teaching in } \\
\text { School District }\end{array}$} & Less than 5 years & $35 \%(n=16 / 46)$ & $38 \%$ & $32 \%$ & $\chi^{2}(2)=0.705, p=.703$ & $\chi^{2}(4)=6.10, p=.19$ \\
\hline & 5 to 10 years & $20 \%(n=9 / 46)$ & $14 \%$ & $24 \%$ & & \\
\hline & More than 10 years & $46 \%(n=21 / 46)$ & $48 \%$ & $44 \%$ & & \\
\hline $\begin{array}{l}\text { Years Working With } \\
\text { Children }\end{array}$ & Less than 10 years & $15 \%(n=7 / 47)$ & $14 \%$ & $16 \%$ & $\chi^{2}(1)=<0.00, p=1$ & $\chi^{2}(4)=2.25, p=.691$ \\
\hline
\end{tabular}

Note. Categories for some variables have been collapsed to protect confidentiality (for more information, please see the Supplemental Materials online). In order to determine whether or not there were significant demographic differences between participants in the in-person and distance learning conditions, we conducted between-subjects $t$-tests on baseline measures of feeling troubled and discipline severity and chi-square analyses on missing data and each demographic variable that determined that there were not any differences in these variables between conditions. Furthermore, chi-square analyses are separated by recoded and original categories. The recoded categories are described in the "Demographic Variables and Coding" portion of the Supplemental Materials, while the original categories represent the between-subjects associated with each unique response per demographic variable. 


\section{Table 2}

Vignettes at three consecutive time points by classroom context

\begin{tabular}{|c|c|c|}
\hline Vignette & In-Person Context & Distance Learning Context \\
\hline Quiet & $\begin{array}{l}\text { Today, Terrell is particularly quiet and is not } \\
\text { participating in the class activities. When you } \\
\text { invite him to join everyone in a song, he avoids } \\
\text { you and says he wants his parent. When you ask } \\
\text { again for his participation, Terrell cries and } \\
\text { causes a disturbance in the classroom for the next } \\
10 \text { minutes. }\end{array}$ & $\begin{array}{l}\text { Today, Terrell is particularly quiet and is not } \\
\text { participating in the distance learning activities. } \\
\text { When you invite him to join everyone in a song, } \\
\text { he avoids the screen and says he wants his } \\
\text { parent. When you ask again for his participation, } \\
\text { Terrell cries and causes a disturbance in the } \\
\text { virtual classroom for the next } 10 \text { minutes. }\end{array}$ \\
\hline (2) & $\begin{array}{l}\text { Three days later, Terrell misbehaves again... } \\
\text { This morning, you notice Terrell is playing with }\end{array}$ & $\begin{array}{l}\text { Three days later, Terrell misbehaves again... } \\
\text { This morning, you notice Terrell is playing with }\end{array}$ \\
\hline Playing & $\begin{array}{l}\text { a pencil instead of participating in class. You ask } \\
\text { him to pay attention. He says, "I don't feel like } \\
\text { it," and continues to play with a pencil. You ask } \\
\text { him again to put down his pencil. He starts to cry } \\
\text { aloud. You then ask him to count to five and take } \\
\text { five deep breaths, but he starts to run around the } \\
\text { classroom instead. You offer to escort him out of } \\
\text { the classroom, but he continues to run around the } \\
\text { room. }\end{array}$ & $\begin{array}{l}\text { a pencil instead of participating in class. You ask } \\
\text { him to pay attention. He says, "I don't feel like } \\
\text { it," and continues to play with a pencil. You ask } \\
\text { him again to put down his pencil. He starts to cry } \\
\text { aloud. You then ask him to count to five and take } \\
\text { five deep breaths, but he starts to run around his } \\
\text { room instead. You offer to switch him to a } \\
\text { breakout room, but he continues to run around } \\
\text { the room. }\end{array}$ \\
\hline (3) & $\begin{array}{l}\text { Today, Terrell is consistently disrupting "circle } \\
\text { time" in the classroom by making funny faces }\end{array}$ & $\begin{array}{l}\text { Today, Terrell is consistently disrupting "circle } \\
\text { time" in the virtual classroom by making funny }\end{array}$ \\
\hline Circle & $\begin{array}{l}\text { and causing visual distractions. In general, } \\
\text { Terrell notices his peers giggling and disrupts the } \\
\text { flow of circle time. When another student in the } \\
\text { class asks Terrell to stop, Terrell laughs very } \\
\text { loudly and then starts making faces at the other } \\
\text { students. }\end{array}$ & $\begin{array}{l}\text { faces and causing visual distractions. In general, } \\
\text { Terrell notices his peers giggling on camera and } \\
\text { disrupts the flow of circle time. When another } \\
\text { student in the class asks Terrell to stop, Terrell } \\
\text { laughs very loudly and then starts making faces } \\
\text { at the other students. }\end{array}$ \\
\hline
\end{tabular}

Note. Keywords used to stimulate the in-person and distance learning conditions are underlined in this table but were not underlined when presented to participants. 


\section{Table 3}

Mixed effects quadratic growth model treated with random effects for subject intercepts and the linear effect of time (subject-level) predicting feeling troubled

\begin{tabular}{lllllll}
\hline Feeling Troubled & $b$ & $t$ & $d f$ & $S E$ & $p$ & $95 \%$ CI \\
\hline Intercept & 1.905 & 15.614 & 100 & 0.122 & $<.001$ & {$[1.67,2.14]$} \\
Condition & 0.121 & 0.497 & 54 & 0.244 & .621 & {$[-0.36,0.60]$} \\
& & & & & & \\
Time (linear) & 0.533 & 3.806 & 100 & 0.134 & $<.001$ & {$[0.26,0.81]$} \\
& -0.106 & -1.652 & 100 & 0.064 & .102 & {$[-0.23,0.02]$} \\
$\begin{array}{l}\text { Time (quadratic) } \\
\text { Condition X Time }\end{array}$ & -0.957 & -3.417 & 100 & 0.280 & $<.001$ & {$[-1.51,-0.41]$} \\
$\begin{array}{l}\text { (linear) } \\
\text { Condition X Time } \\
\text { (quadratic) }\end{array}$ & 0.424 & 3.303 & 100 & 0.128 & .001 & {$[0.17,0.68]$} \\
\hline
\end{tabular}

Note. $95 \%$ confidence intervals (CIs) are presented in brackets for all results. 


\section{Table 4}

Mixed effects quadratic growth model treated with random effects for subject intercepts and the linear effect of time (subject-level) predicting discipline severity

\begin{tabular}{lllllll}
\hline Discipline Severity & $b$ & $t$ & $d f$ & $S E$ & $p$ & $95 \%$ CI \\
\hline Intercept & 1.297 & 12.065 & 98 & 0.107 & $<.001$ & {$[1.09,1.51]$} \\
Condition & -0.022 & -0.103 & 51 & 0.215 & .918 & {$[-0.44,0.40]$} \\
& & & & & & \\
Time (linear) & 0.477 & 3.640 & 98 & 0.131 & $<.001$ & {$[0.22,0.73]$} \\
& -0.116 & -1.997 & 98 & 0.060 & .05 & {$[-0.23,-$} \\
$\begin{array}{l}\text { Time (quadratic) } \\
\text { Condition X Time }\end{array}$ & -0.743 & -2.835 & 98 & 0.262 & .005 & {$[-1.26,-0.23]$} \\
$\begin{array}{l}\text { (linear) } \\
\text { Condition X Time }\end{array}$ & 0.308 & 2.642 & 98 & 0.117 & 0.01 & {$[0.08,0.54]$} \\
(quadratic) & & & & & & \\
\hline
\end{tabular}

Note. $95 \%$ confidence intervals (CIs) are presented in brackets for all results. 


\section{Figure 1}

Averages of feeling troubled (panel A) and discipline severity (panel B) across three vignettes by classroom context
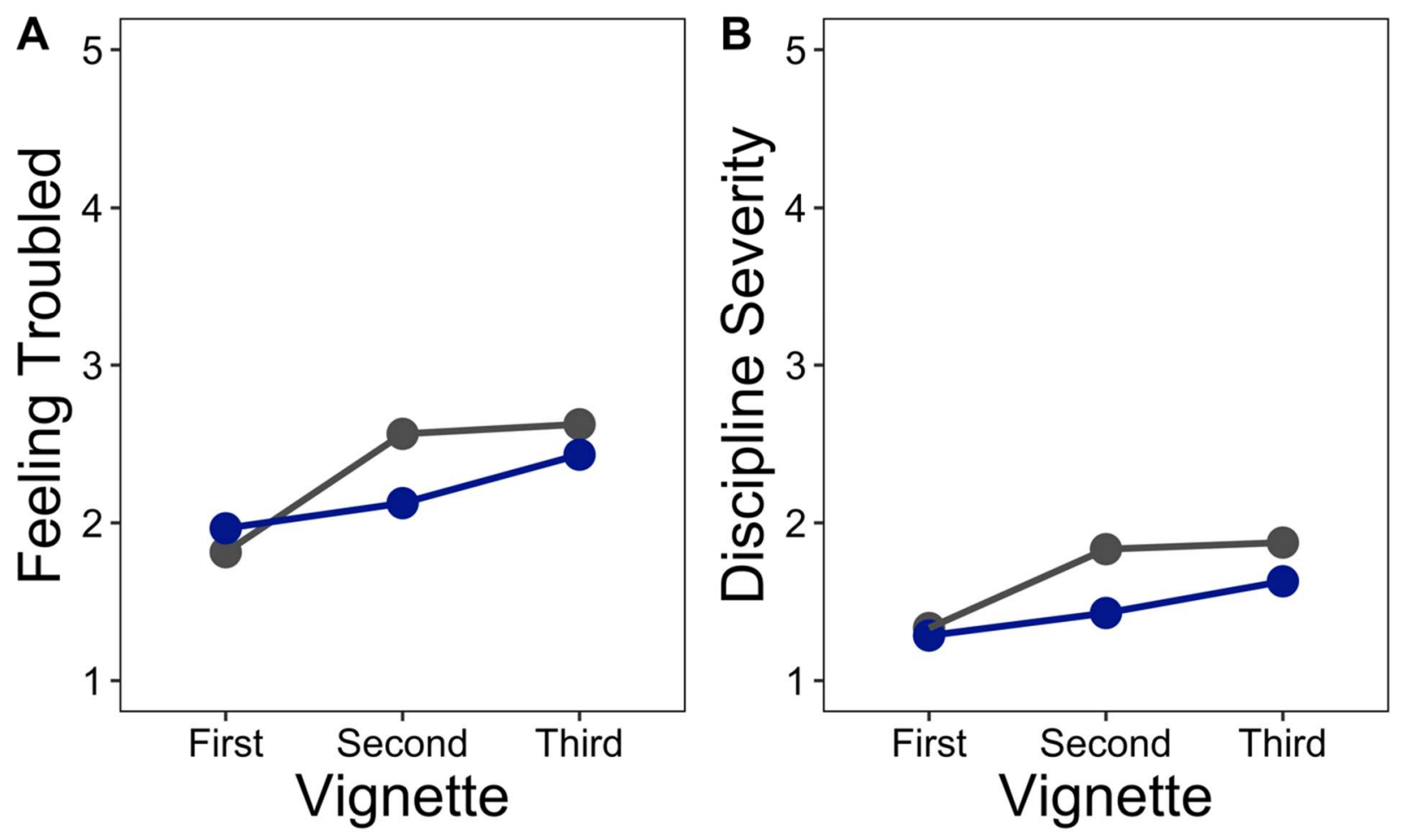

Condition Distance Learning $\odot$ In-Person 